\title{
Revegetation in abandoned quarries with landfill stabilized waste and gravels: water dynamics and plant growth - a case study
}

\author{
Cheng-liang Zhang ${ }^{1, *}$, Jing-jing Feng ${ }^{2,3,},{ }^{*}$ Li-ming Rong ${ }^{1}$, and Ting-ning Zhao ${ }^{2}$ \\ ${ }^{1}$ Beijing Key Lab of Industrial Land Contamination and Remediation, Environmental Protection Research \\ Institute of Light Industry, 100089, Beijing, China \\ ${ }^{2}$ School of Soil and Water Conservation, Beijing Forestry University, 100083, Beijing, China \\ ${ }^{3}$ School of Environmental Science and Engineering, Shanghai Jiao Tong University, 200240 Shanghai, China \\ *These authors contributed equally to this work.
}

Correspondence to: Ting-ning Zhao (zhtning@bju.edu.cn)

Received: 10 July 2017 - Discussion started: 21 July 2017

Revised: 12 September 2017 - Accepted: 24 September 2017 - Published: 2 November 2017

\begin{abstract}
Large amounts of quarry wastes are produced during quarrying. Though quarry wastes are commonly used in pavement construction and concrete production, in situ utilization during ecological restoration of abandoned quarries has the advantage of simplicity. In this paper, rock fragments $2-3 \mathrm{~cm}$ in size were mixed with landfill stabilized waste (LSW) in different proportions (LSW : gravel, $R_{\mathrm{L}}$ ), which was called LGM. The water content, runoff and plant growth under natural precipitation were monitored for 2 years using a runoff plot experiment. LGM with a low fraction of LSW was compacted to different degrees to achieve an appropriate porosity; water dynamics and plant growth of compacted LGM were studied in a field experiment. The results showed the following: (1) LGM can be used during restoration in abandoned quarries as growing material for plants. (2) $R_{\mathrm{L}}$ had a significant effect on the infiltration and water-holding capacity of LGM and thus influenced the retention of precipitation, water condition and plant growth. LGM with $R_{\mathrm{L}}$ ranging from $8: 1$ to $3: 7$ was suitable for plant growth, and the target species grew best when $R_{\mathrm{L}}$ was $5: 5$. (3) Compaction significantly enhanced water content of LGM with a low $R_{\mathrm{L}}$ of $2: 8$, but leaf water content of plants was lower or unchanged in the more compacted plots. Moderate compaction was beneficial to the survival and growth of Robinia pseudoacacia L. Platycladus orientalis (L.) Franco and Medicago sativa L. were not significantly affected by compaction, and they grew better under a high degree of compaction, which was disadvantageous for the uppermost layer of vegetation.
\end{abstract}

\section{Introduction}

During the process of urbanization and urban construction, the quarrying industry has developed quickly in order to satisfy the growing demand for stones (Duan et al., 2008). Large amounts of quarry wastes are produced during quarrying. In 2006, the by-product of mining and quarrying accounted for $55 \%$ of industrial waste in Europe (Castro-Gomes et al., 2012). Eighty percent of stones or soils extracted during quarrying are wasted (André et al., 2014). Thirty percent and forty percent of marble blocks are wasted as powder and rock fragments, respectively (Akbulut and Gürer, 2007). Quarry wastes occupy a lot of land, have a low aesthetic value, and may lead to soil erosion, landslide or debris flow.

Reuse is an environmentally friendly way to deal with quarry wastes. Coarse and fine aggregates are commonly used in quarry settlement, the production of concrete, mortars and ceramic tiles, and highway construction (Amin et al., 2011; Safiuddin et al., 2010, 2007). The coarse-waste aggregates could also be used to make high-value-added products such as sculpture (Castro-Gomes et al., 2012), while the ultra-fine marble wastes are used in various industrial processes such as plastic production, paper production, pharmaceuticals industry and agriculture (Gazi et al., 2012). However, the reuse of quarry waste on a national scale is primarily constrained by economic aspects such as transport (Castro-Gomes et al., 2012) as well as the lack of industrial symbiosis. Most quarrying and stone processing activities are performed by small to medium enterprises. This fragmented quarry industry shares hardly any information, 
services and by-product resources with other industrial practitioners in order to add value, reduce costs, and improve environment, leading to inefficient waste management (Gazi et al., 2012; Rubio et al., 2010). As stated by Tiruta-Barna et al. (2007), members of the industry lacked unambiguous references concerning the feasibility of specific reuse projects. Considering the current situation, the in situ utilization of quarry waste during ecological restoration of abandoned quarries has the advantage of simplicity.

Water and nutrient deficiencies are the main environmental factors constraining natural recovery in abandoned quarries. These disadvantageous site conditions have to be changed to facilitate plant survival and growth (Luna et al., 2016). In the last decade, many arable topsoil materials were bought and transported from other places to replace or cover the barren spoil or waste in abandoned quarries or mines in China, which was very expensive, accounting for about $50 \%$ of the total cost of restoration. The environment of the places where surface soils are taken may also be adversely affected. Soillike materials containing high values of nutrients such as sewage sludge and waste compost are effective topsoil substitutes because of their economic and environmental advantages (Luna et al., 2016; Forján et al., 2016; Jordán et al., 2017). Landfill stabilized waste (LSW) is the aged municipal solid waste which has gone through a series of microbiological processes in closed landfills. It is similar to municipal waste compost regarding its source, production process and the properties of end products. Previous research indicated its promising potential as a growth substrate for plants (Zhang et al., 2017; Zhou et al., 2015; Feng et al., 2017). However, compared with sewage sludge and waste compost, LSW has not been fully exploited, and the research on its properties and application is still limited.

When LSW is mined from the landfill, the original structure is inevitability destroyed. With a high compressibility, LSW lacks hydro-structural stability and is very sensitive to compaction (Schäffer et al., 2008). By contrast, quarry spoil and waste may be highly compacted by machines or vehicles and thus have low hydraulic conductivity. If LSW is directly placed on this impervious layer, slip surface may generate between the two layers with a dramatic difference in hydraulic conductivity or within the LSW layer because of the low shear strength of unconsolidated LSW (Okura et al., 2003). As a result, instead of directly topsoiling with LSW, we mixed it with gravels $(2-3 \mathrm{~cm}$ in size) in different proportions, reusing rock fragments of quarry wastes as part of the growth substrate for plants, which is called LGM hereinafter. Not only do the embedded gravels constitute the primary fabric and thus enhance the stability of the mixture, the surface gravels can also reduce soil evaporation and conserve surface water (Yuan et al., 2009) and prevent fine earth from wind and splash erosion (Jomaa et al., 2012).

When the fraction of LSW is low and most macropores between rock fragments are not filled with LSW, the waterholding capacity and thus the water condition may be disad-

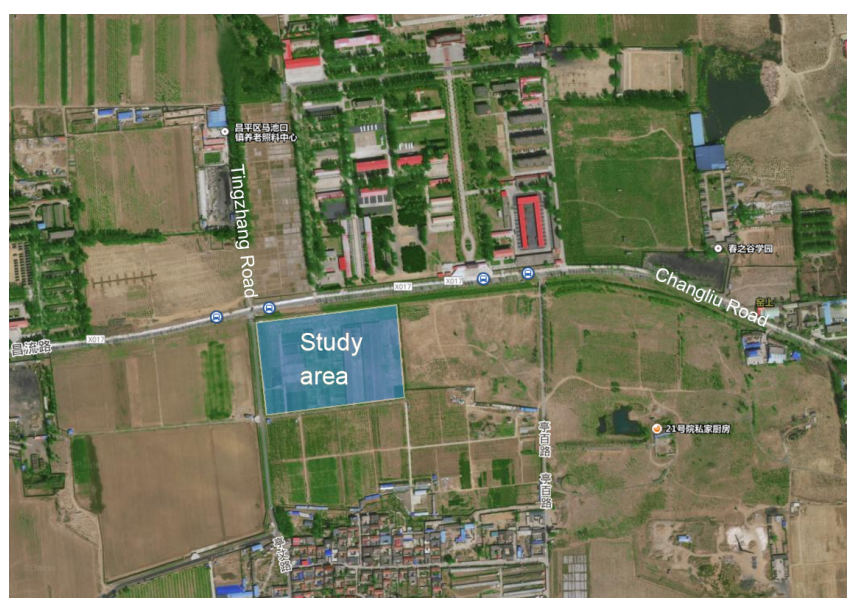

Figure 1. Map of the study area.

vantageous for plant growth. In order to achieve an appropriate porosity, LGM with a low LSW : gravel ratio $(2: 8)$ was compacted to different degrees. The effects of compaction on water condition and plant growth were also studied.

\section{Materials and methods}

\subsection{Study area}

The research was conducted in the Ecological Restoration Research Base of Environmental Protection Research Institute of Light Industry, located in Changping County, Beijing $\left(40^{\circ} 9^{\prime} 56.73^{\prime \prime} \mathrm{N}, 116^{\circ} 9^{\prime} 1.04^{\prime \prime} \mathrm{E} ; 57 \mathrm{~m}\right.$ a.s.l.). The texture of the surrounding farmland is sandy clay, but it can be sandy loam or loamy clay depending on the land use type. The map of the study area is shown in Fig. 1. Beijing has a continental monsoon climate with a rainy season from June to September. The mean annual precipitation is $600 \mathrm{~mm}$, the mean annual temperature is $8-12^{\circ}$ and the mean annual evaporation is $1800-2000 \mathrm{~mm}$.

\subsection{Materials}

In 2012, LSW was taken from five landfills in different districts of Beijing, transported to the study site and mixed. Texture, chemical properties such as nutrient and heavy metal contents, concentrations of semi-volatile contaminants, and the most probable number of coliforms were tested. The texture of LSW was in accordance with sandy clay loam; generally, the nutrient contents of LSW were higher than the local agricultural soil; the concentrations of heavy metals and organic contaminants were lower than the national limits or similar to the concentrations in natural soil; the most probable number of coliforms was $486 \pm 188 \mathrm{MPN} \mathrm{g}^{-1}$. Basic physical and chemical properties are shown in Table 1. 
Table 1. Basic physical and chemical properties of LSW ( \pm standard deviation).

\begin{tabular}{lrlr}
\hline Objects & Mean values & Objects & Mean values \\
\hline Sand $(0.05002 \mathrm{~mm}, \%)$ & 64 & $\mathrm{As}\left(\mathrm{mg} \mathrm{kg}^{-1}\right)$ & $10.1 \pm 5.5$ \\
Silt $(0.002-0.05 \mathrm{~mm}, \%)$ & 16 & $\mathrm{Cr}\left(\mathrm{mg} \mathrm{kg}^{-1}\right)$ & $91.2 \pm 46.4$ \\
Clay $(<0.002 \mathrm{~mm}, \%)$ & 20 & $\mathrm{Cu}\left(\mathrm{mg} \mathrm{kg}^{-1}\right)$ & $77.6 \pm 51.6$ \\
Total K $\left(\mathrm{g} \mathrm{kg}^{-1}\right)$ & $25.5 \pm 7.7$ & $\mathrm{Ni}\left(\mathrm{mg} \mathrm{kg}^{-1}\right)$ & $31.9 \pm 12.4$ \\
Available K $\left(\mathrm{mg} \mathrm{kg}^{-1}\right)$ & $503 \pm 124$ & $\mathrm{~Pb}\left(\mathrm{mg} \mathrm{kg}^{-1}\right)$ & $54.2 \pm 30.8$ \\
Total N $\left(\mathrm{g} \mathrm{kg}^{-1}\right)$ & $1.95 \pm 0.51$ & $\mathrm{Zn}\left(\mathrm{mg} \mathrm{kg}^{-1}\right)$ & $215 \pm 136.1$ \\
Nitrate-N $\left(\mathrm{mg} \mathrm{kg}^{-1}\right)$ & $105.9 \pm 105.1$ & $\mathrm{Cd}\left(\mathrm{mg} \mathrm{kg}^{-1}\right)$ & $0.29 \pm 0.05$ \\
Ammonium-N $\left(\mathrm{mg} \mathrm{kg}^{-1}\right)$ & $9.21 \pm 4.78$ & $\mathrm{Hg}\left(\mathrm{mg} \mathrm{kg}^{-1}\right)$ & $0.78 \pm 0.45$ \\
Total $\mathrm{P}\left(\mathrm{g} \mathrm{kg}^{-1}\right)$ & $1.12 \pm 0.33$ & $\mathrm{pH} \mathrm{value}$ & 8.2 \\
Available $\mathrm{P}\left(\mathrm{mg} \mathrm{kg}^{-1}\right)$ & $75.08 \pm 145.87$ & Organic matter $\left(\mathrm{g} \mathrm{kg}^{-1}\right)$ & $40.12 \pm 22.27$ \\
\hline
\end{tabular}

Gravels were bought from the local market. The main compositions were limestone, granite and quartzite, which were the most common parent rocks around the study area. The mean values (with standard deviation) of maximum, medium and minor axis length were $31 \pm 24,21 \pm 4$ and $15 \pm 4 \mathrm{~mm}$, respectively. LSW and gravels were mixed with a mixing machine in different fractions. The LSW : gravel ratios by volume $\left(R_{\mathrm{L}}\right)$ were $8: 1,7: 3,5: 5,3: 7$ and $1: 8$, which were marked as L1, L2, L3, L4 and L5. LGMs were oven-dried, weighed and filled into $660 \mathrm{~cm}^{3}$ cubic flowerpots. They were saturated and weighed to calculate porosity (saturated water content) and then allowed to drain freely under gravity for 1 day and weighed to calculate field capacity. The upper openings of the flowerpots were sealed with plastic film to prevent evaporation, and gauze was used to avoid leakage of the finer grains through the drain holes.

\subsection{Runoff plots of LGM}

\subsubsection{Setting of runoff plots}

In 2012, five $2.8 \mathrm{~m}$ wide, $3.6 \mathrm{~m}$ long runoff plots with a slope degree of $38^{\circ}$ were set. LGM (L1-L5) that was $70 \mathrm{~cm}$ thick was spread on impervious liners and was settled for 1 year. Ruderal species such as Setaria viridis (L.) Beauv., Digitaria sanguinalis (L.) Scop., Amaranthus retroflexus L., Bidens parviflora Willd., Pharbitis nil (L.) Choisy, Echinochloa crus-galli (L.) Beauv., Chenopodium album L. and Metaplexis japonica (Thunb.) Makino colonized the plots during the 1-year settlement. During the rainy season the vegetation coverage from L1 to L4 was $100 \%$, while that of L5 was about $50 \%$. Litters in two $1 \mathrm{~m}^{2}$ quadrats for each runoff plot were collected in November 2014 to evaluate the abundance of ruderals.

\subsubsection{Water content}

The volumetric water content at $10-50 \mathrm{~cm}$ depths was measured using a capacitance probe (Diviner 2000, Sentek Pty Ltd., Australia) from August 2013 to August 2015, three times a month; these data were averaged to calculate annual and monthly mean water content. The volumetric water content was also measured every sunny day from May to $\mathrm{Au}-$ gust 2014; these data were used to study the relationship between soil moisture and precipitation during the rainy season.

\subsubsection{Retention of precipitation}

A multiple regression model is fitted as follows:

$Y=\alpha+\beta_{1} X_{1}+\beta_{2} X_{2}$,

where $X_{1}, X_{2}$ and $Y$ represent antecedent water content (\%), precipitation $(\mathrm{mm})$ and water content 1 day after the rainfall event $(\%)$, respectively. The partial regression coefficient for precipitation $\left(\beta_{2}\right)$ is used as a measure of water conservation, i.e., the average increment of water content each additional precipitation is associated with, for any given antecedent water content (Cohen et al., 2003). Retention of precipitation, which is the percentage of precipitation able to infiltrate into and was stored in the LGM profile after one night's drainage is calculated as follows:

$\mathrm{RP}=\beta_{2} \times D$,

where RP is the retention of precipitation and $D$ is the depth of LGM.

\subsubsection{Runoff}

Surface and subsurface runoff were collected separately 1 day after each rainfall event from June to September (the rainy season) in 2013 and 2014. During the experimental period, there were altogether 32 cases of rainfall: 12 cases of light rain $\left(<10 \mathrm{~mm} \mathrm{~d}^{-1}\right), 15$ cases of moderate rain $(10$ $25 \mathrm{~mm} \mathrm{~d}^{-1}$ ) and 5 cases of heavy rain $\left(>25 \mathrm{~mm} \mathrm{~d}^{-1}\right)$.

\subsubsection{Plant growth}

After clearing the colonized ruderals, a seed mixture of Robinia pseudoacacia L. (leguminous tree), Festuca elata 
Keng ex E. B. Alexeev (perennial grass), Orychophragmus violaceus (L.) O.E. Schulz (annual or biennial herb) and $V i$ ola philippica Cav. (perennial herb) was sowed with a density of $15 \mathrm{~g} \mathrm{~m}^{-2}$ (6:2:1:1 by mass) in June 2015 . A previous study indicated its efficiency in fast revegetation and providing a stable soil cover (Feng et al., 2015). Vegetation coverage was measured from August to November 2015 using eight $1 \mathrm{~m}^{2}$ fixed sample plots (Xie, 2010). The two tallest $R$. pseudoacacia seedlings in each sample plot were cut in November 2015, oven-dried for $12 \mathrm{~h}$, and the biomass was measured.

\subsection{Compacted plots of LGM}

\subsubsection{Setting of compacted plots}

Five $5 \mathrm{~m}$ long, $3 \mathrm{~m}$ wide and $1 \mathrm{~m}$ deep plots were dug and filled with the LGM with a low LSW : gravel ratio of $2: 8$ $\left(R_{\mathrm{L}}=2: 8\right)$. LGM was compacted to different degrees using a vibratory roller.

\subsubsection{Determination of theoretical porosity}

Because the porosity of compacted LGM was difficult to attain, it was calculated theoretically, assuming that the porosity and particle density of the loose LSW were constant:

$M / \rho=V_{0} \times\left(1-P_{0}\right)=V_{\mathrm{c}} \times\left(1-P_{\mathrm{c}}\right)$,

where $\rho$ is particle density, $P_{0}$ or $P_{\mathrm{c}}$ is the porosity of LGM before or after compaction, $M$ is the mass of LGM particle, and $V_{0}$ or $V_{\mathrm{c}}$ is the volume of LGM before or after compaction. Hence,

$P_{\mathrm{c}}=1-\left(1-P_{0}\right) \times V_{0} / V_{\mathrm{c}}$.

$P_{0}$ was measured as described in Sect. 2.2; $V_{0}$ and $V_{\mathrm{c}}$ were measured before and after the compaction.

\subsubsection{Water content and the retention of precipitation}

The volumetric water content at $10-100 \mathrm{~cm}$ depth was measured from three PVC tubes in each compacted plot using the capacitance probe. The measurement of water content and the calculation of RP in the compacted plots were the same as the measurement and calculation in the runoff plots.

\subsubsection{Plant growth}

In total, 56 R. pseudoacacia and 30 Medicago sativa L. (leguminous herb) seeds were sowed, and 60 Platycladus orientalis (L.) Franco (evergreen conifer) seedlings were transplanted in each compacted plot after compaction in 2012. No water or nutrients were applied. The germination rate was measured in October 2012 and the survival rate was measured in October 2014. From 2013 to 2014, three times a month during the rainy season, leaves were collected at
12:00, weighed, oven-dried and weighed again to calculate leaf water content; the height and stem base diameter of each woody seedling were measured in October; 15 individuals of $M$. sativa were cut after flowering and oven-dried, and the aboveground biomass was measured.

\subsection{Data analysis}

Data were log-transformed and normalized when necessary. One-way analysis of variance and a least significant difference test were used to compare height and biomass of $R$. pseudoacacia seedlings growing in LGMs with different $R_{\mathrm{L}} \mathrm{s}$. This test was also used to compare leaf water content, height or diameter growth (for trees), and biomass (for herbs) of seedlings growing in different compacted LGM plots. Friedman's test was used to compare water content, runoff and vegetation coverage of different runoff plots. A linear regression model was used to describe the relationship between antecedent water content, precipitation and water content. SPSS software was used for data analysis.

\section{Results}

\subsection{LGM with different fractions of LSW}

\subsubsection{Water content and use efficiency of precipitation}

As shown in Table 2, the field capacity of LGM decreased significantly with decreasing $R_{\mathrm{L}}(P<0.01)$, reflecting the positive relationship between water-holding capacity and $R_{\mathrm{L}}$ since most capillary pores were provided by LSW. The saturated water content was lowest when $R_{\mathrm{L}}$ was intermediate and LSW exactly filled the voids between the gravels, but the difference was not significant.

The annual mean, maximum and minimum monthly mean water contents of all LGM plots were much lower than field capacity, indicating prolonged soil water deficit. However, plants may respond quickly to pulsed rainfall events and make the most of precipitation (Huxman et al., 2004). $R_{\mathrm{L}}$ had a positive effect on the retention of precipitation. With a decreasing $R_{\mathrm{L}}$, the percentage of precipitation which was able to infiltrate into and was stored in the LGM profile dropped from 70.5 to $24.5 \%$.

\subsubsection{Runoff generation}

Under light rains, surface or subsurface runoff did not change significantly with $R_{\mathrm{L}}$, but the volume of total runoff in L5 was significantly higher than in L2 and L3 $(P<0.05)$. During moderate rainfalls, the surface runoff in L2 was significantly lower than in L3, L4 and L5 $(P<0.05)$, but subsurface or total runoff did not change significantly with $R_{\mathrm{L}}$. During heavy rainfalls, surface, subsurface or total runoff did not change significantly with $R_{\mathrm{L}}$. However, as shown in Fig. 2, generally, during moderate and heavy rainfalls, subsurface 
Table 2. Hydro-physical properties of LGM.

\begin{tabular}{lcccrrr}
\hline LSW fraction & \multicolumn{5}{c}{ Moisture content $(\%)$} & \multirow{2}{*}{ RP (\%) } \\
\cline { 2 - 6 } & $\begin{array}{c}\text { Saturated moisture } \\
\text { content }\end{array}$ & $\begin{array}{c}\text { Field } \\
\text { capacity }\end{array}$ & $\begin{array}{c}\text { Annual } \\
\text { mean }\end{array}$ & $\begin{array}{c}\text { Maximum } \\
\text { monthly mean }\end{array}$ & $\begin{array}{c}\text { Minimum } \\
\text { monthly mean }\end{array}$ \\
\hline L1 & $48.9 \pm 2.0$ & $42.9 \pm 2.0$ & $8.7 \pm 1.6$ & 10.9 & 6.8 & 70.5 \\
L2 & $39.2 \pm 10.8$ & $33.2 \pm 10.8$ & $4.8 \pm 0.8$ & 5.8 & 3.6 & 34.0 \\
L3 & $31.6 \pm 0.1$ & $25.7 \pm 0.1$ & $5.2 \pm 1.3$ & 7.6 & 3.8 & 49.0 \\
L4 & $34.3 \pm 4.1$ & $13.6 \pm 3.4$ & $3.2 \pm 0.7$ & 4.5 & 2.3 & 26.5 \\
L5 & $41.9 \pm 1.2$ & $8.7 \pm 1.2$ & $2.6 \pm 0.8$ & 3.9 & 1.9 & 24.5 \\
\hline
\end{tabular}

Note: the multiple regression fitted to attain RP was significant at the 0.01 level. Antecedent water content and precipitation accounted for $73.4-87.6 \%$ variance of water content 1 day after the rainfall event.

Table 3. Height and single plant biomass $R$. pseudoacacia.

\begin{tabular}{lcc}
\hline $\begin{array}{l}\text { Runoff } \\
\text { plot }\end{array}$ & $\begin{array}{c}\text { Height } \\
(\mathrm{cm})\end{array}$ & $\begin{array}{c}\text { Aboveground biomass } \\
\text { of single plant }(\mathrm{g})\end{array}$ \\
\hline L1 & $22 \pm 6^{\mathrm{b}}$ & $0.759 \pm 0.159^{\mathrm{b}}$ \\
L2 & $25 \pm 8^{\mathrm{b}}$ & $0.958 \pm 0.317^{\mathrm{b}}$ \\
L3 & $35 \pm 6^{\mathrm{a}}$ & $2.035 \pm 0.480^{\mathrm{a}}$ \\
L4 & $26 \pm 7^{\mathrm{b}}$ & $0.917 \pm 0.095^{\mathrm{b}}$ \\
L5 & $11 \pm 4^{\mathrm{c}}$ & $0.171 \pm 0.031^{\mathrm{b}}$ \\
\hline
\end{tabular}

Note: the same letter indicates that the difference is not significant at the 0.05 level.

and total runoff had a tendency to increase with decreasing $R_{\mathrm{L}}$. The failure in passing the significance test may result from the high variation in runoff under natural precipitation, indicated by its high standard deviation, which may be caused by the different intensity and/or duration of each rainfall event and the antecedent water content (Liu et al., 2012).

\subsubsection{Plant growth}

From August to December, vegetation coverage in L1, L2, L3, L4 and L5 was 28.9-86.0, 20.2-96.0, 37.2-93.4, 24.882.3 and $6.2-43.0 \%$, respectively. Generally, the speed of vegetation formation, the mean coverage and the duration of land cover were similar in $\mathrm{L} 1$ to L4, but L5 showed distinctly lower values. The height and biomass of $R$. pseudoacacia were significantly greater in L3 $(P<0.01)$; the differences were not significant between L1, L2 and L4; L5 still had the lowest performance (Table 3 ).

\subsubsection{Litter}

The dry weights of ruderal litter in L1, L2, L3, L4 and L5 were $0.283,0.257,0.197,0.217$ and $0.086 \mathrm{~kg} \mathrm{~m}^{-2}$, respectively, which showed a decreasing tendency with decreasing $R_{\mathrm{L}}$.

\subsection{Compacted LGM with low fraction of LSW}

\subsubsection{Water condition of compacted LGM}

As shown in Table 4, the annual mean water content of LGM $\left(R_{\mathrm{L}}=2: 8\right)$ increased significantly with an increasing degree of compaction $(P<0.01)$. The theoretical porosity was 13.3-26.1\% higher than the annual mean water content in CL1-CL4 but $2.1 \%$ lower in CL5, indicating its poor aeration, which may hinder microbial activity, nutrient mineralization, and the uptake of water and nutrient by plants.

Compaction had a positive effect on the retention of precipitation. With an increasing compaction degree, the percentage of precipitation which was able to infiltrate into and was stored in the LGM profile increased from 34 to $97 \%$.

\subsubsection{Plant growth in the compacted LGM}

\section{Leaf water content}

Leaf water content of $R$. pseudoacacia and $M$. sativa decreased significantly with an increasing degree of compaction $(P<0.05)$. But the difference in $P$. orientalis was not significant between compacted plots (Table 5).

\section{Survival rate}

The germination rates of $R$. pseudoacacia in CL1, CL2, CL3, CL4 and CL5 were 95, 87, 92, 64 and $34 \%$, respectively, in 2012; the survival rates were 59, 56, 56, 28 and $31 \%$, respectively, in 2014.

The survival rates of $P$. orientalis in CL1, CL2, CL3, CL4 and CL5 were 100, 97, 97, 95, and 95\%, respectively, in 2012 and were $85,83,83,88$ and $88 \%$, respectively, in 2014 .

\section{Growth rate}

Compaction had a significant suppressive effect on height or diameter growth of $R$. pseudoacacia $(P<0.01)$, but the height and stem base diameter of $P$. orientalis increased with an increasing degree of compaction (Fig. 3). 

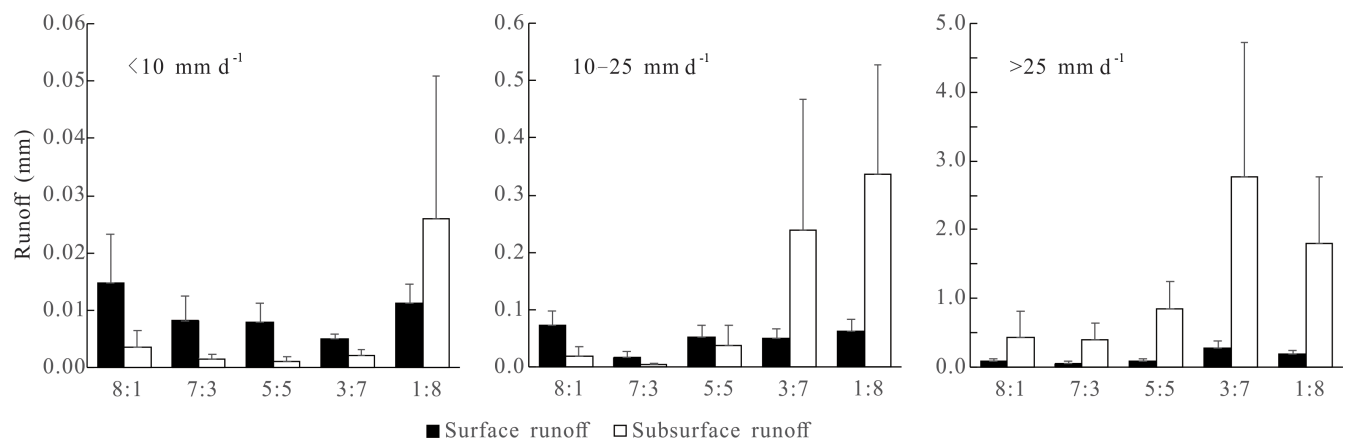

Figure 2. Average runoff generated in LGM slopes under natural precipitation.

Table 4. Hydro-physical properties of LGM $\left(R_{\mathrm{L}}=2: 8\right)$ with different compaction degrees.

\begin{tabular}{lrrrrr}
\hline Compacted plot & \multicolumn{4}{c}{ Moisture content (\%) } & \multirow{2}{*}{ RP (\%) } \\
\cline { 2 - 5 } & $\begin{array}{r}\text { Theoretical } \\
\text { porosity }\end{array}$ & $\begin{array}{r}\text { Annual } \\
\text { mean }\end{array}$ & $\begin{array}{r}\text { Maximum } \\
\text { monthly mean }\end{array}$ & $\begin{array}{r}\text { Minimum } \\
\text { monthly mean }\end{array}$ & \\
\hline CL1 & 31.1 & $5.0 \pm 0.8$ & 6.1 & 4.1 & 34 \\
CL2 & 26.8 & $6.4 \pm 1.2$ & 8.0 & 5.0 & 45 \\
CL3 & 22.1 & $7.8 \pm 1.2$ & 9.4 & 6.5 & 44 \\
CL4 & 21.1 & $7.7 \pm 1.2$ & 8.9 & 6.4 & 53 \\
CL5 & 13.3 & $15.4 \pm 2.1$ & 17.8 & 13.4 & 97 \\
\hline
\end{tabular}

Note: the multiple regression fitted to attain RP was significant $(P<0.01)$. Antecedent water content and precipitation accounted for $65.7-86.1 \%$ variance of water content 1 day after the rainfall event.

The effect of compaction on biomass of $M$. sativa was positive and significant $(P<0.01)$. The difference between CL1 and CL2 was not significant, but the biomass was significantly higher in CL3-CL5 compared to CL1 in both 2014 and 2015 (Fig. 4).

\section{Discussion}

\subsection{Using LGM as growth substrate for plants}

LSW is a soil-like material containing high values of organic matter and other nutrients such as nitrogen and potassium, and it thus has a promising prospect as topsoil substitute during environmental restoration. However, unconsolidated LSW is unstable and prone to wind or water erosion especially when its structure is destroyed during landfill mining. When LSW is mixed with rock fragments, friction force and interlock capacity would increase while surface runoff and soil erosion would decrease (Descroix et al., 2001). Compared to LSW, less surface runoff was generated in LGM regardless of $R_{\mathrm{L}}$ or precipitation intensity (Zhang et al., 2017). The effect of $R_{\mathrm{L}}$ on surface runoff was not significant, probably because the infiltration rate was always higher than the intensity of precipitation, and thus most rainfall infiltrated into LGM profile, held by capillary force or discharging as subsurface runoff (Cerdà, 1998). When the proportion of LSW was low, more subsurface runoff was generated, which may lead to higher underground erosion of fine grains. With a low $R_{\mathrm{L}}$, the fine grains are also likely to move down with infiltration through the macropores between the gravels, in gentle slopes or even on flat land, leaving a layer of pure gravels advantageous for plant growth. This phenomenon of soil leakage is common in the karst regions (Wang et al., 2014). As a result, $R_{\mathrm{L}}$ not only influences the current water condition of LGM, it also has a significant effect on its development.

Though the water content of LGM was only $15.4-50.9 \%$ of LSW under natural precipitation (Zhang et al., 2017), plants grew well in L1-L4. However, the target species, $R$. pseudoacacia grew best in L3, which may result from the less severe interspecific competition compared to L1 and L2. A higher contents of nutrients provided by LSW may be more beneficial to ruderals and other herbaceous species (Le Stradic et al., 2014), which was consistent with the higher amount of ruderal litters in L1 and L2. L5 showed the poorest water condition and plant growth because water cannot be held within macropores between gravels, and thus LGM with this $R_{\mathrm{L}}$ is not recommended unless other ameliorative measures are supplemented. 
Table 5. Average leaf water contents of plants growing in the compacted LGM $\left(\mathrm{g} \mathrm{g}^{-1}\right)$.

\begin{tabular}{lccccc}
\hline Plant species & CL1 & CL2 & CL3 & CL4 & CL5 \\
\hline R. pseudoacacia & $2.25 \pm 0.09^{\mathrm{a}}$ & $2.19 \pm 0.06^{\mathrm{a}}$ & $2.20 \pm 0.13^{\mathrm{ab}}$ & $1.99 \pm 0.06^{\mathrm{b}}$ & $1.88 \pm 0.09^{\mathrm{b}}$ \\
P. orientalis & $2.04 \pm 0.17$ & $2.16 \pm 0.14$ & $2.10 \pm 0.16$ & $2.07 \pm 0.15$ & $2.12 \pm 0.17$ \\
M. sativa & $3.79 \pm 0.15^{\mathrm{a}}$ & $3.50 \pm 0.18^{\mathrm{a}}$ & $3.29 \pm 0.19^{\mathrm{a}}$ & $3.13 \pm 0.22^{\mathrm{ab}}$ & $2.45 \pm 0.18^{\mathrm{b}}$ \\
\hline
\end{tabular}

Note: the same letter indicates that the difference between different compacted plots is not significant at the 0.05 level.
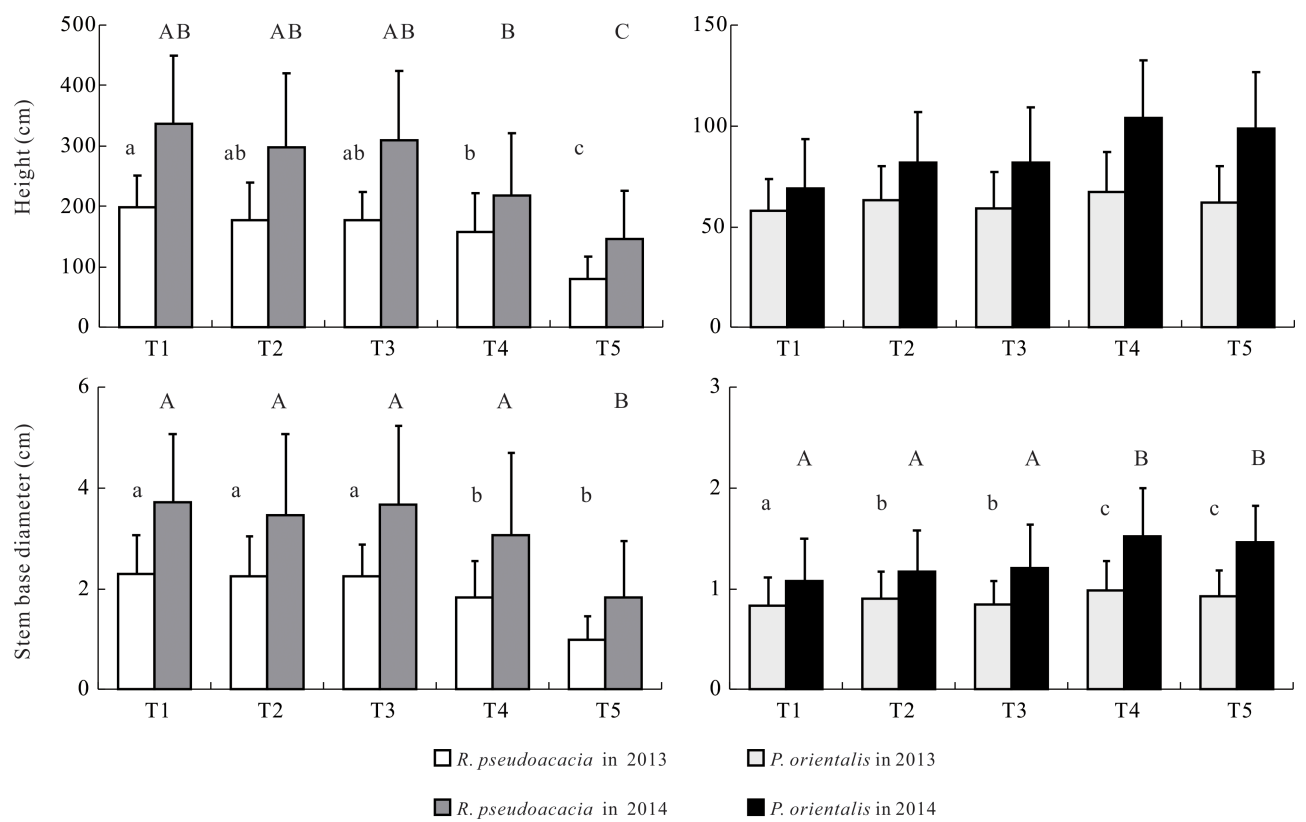

Figure 3. Wood growth. Note: the same lower-case or capital letter indicates that in 2013 or 2014 the difference between different compacted plots is not significant at the 0.05 level.

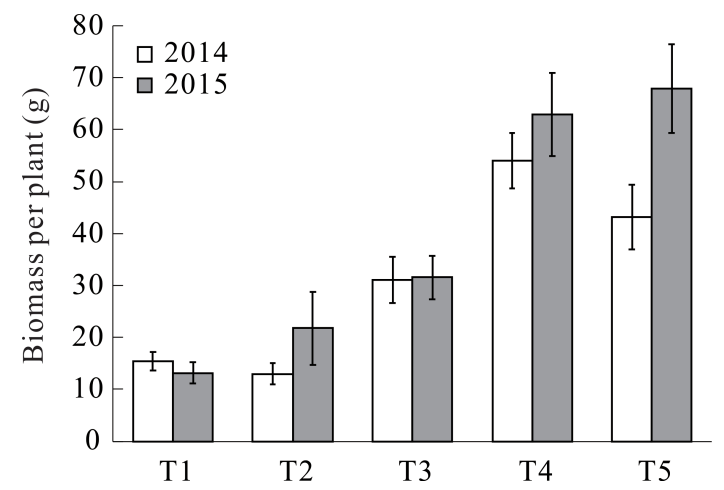

Figure 4. Herb growth.

\subsection{Using compacted LGM as growth substrate for plants}

Compaction had a significant effect on improving waterholding capacity. With an increasing compaction degree, the annual mean water content increased from 5 to $15.4 \%$, and the retention of precipitation increased from 34 to $97 \%$. However, leaf water content of $R$. pseudoacacia was significantly lower in the compacted plots, indicating water deficit. $R$. pseudoacacia is a fast-growing species with a deep root system. The high transpiration demand was not satisfied, probably for two reasons: firstly, soil water in the compacted plots may be harder to extract because of lower water potential and hydraulic conductivity; secondly, water uptake may decrease because of the constrained development of roots (Sharrow, 2007; Nadian et al., 1996).

An unignorable deficiency of the experiment was that plant roots could grow through the $1 \mathrm{~m}$ thick LGM layer and absorb water from the underlying natural soil because impervious liner was not set between LGM and the underlying soil. Plants growing in uncompacted LGM in a real environment, i.e., abandoned quarries, should not have this good performance because the only water source was LGM, which contained only $5 \%$ water under natural precipitation. $R$. pseudoacacia growing in CL3 should have the best performance in the real environment although the germination, survival 
and growth were not significantly different from CL1 in our experiment, which was consistent with Jeldes et al. (2013).

The leaf water content of $P$. orientalis was not affected by compaction, and seedlings grew better in the more compacted plots, indicating that water or compaction degree were not the key factor constraining growth rate. Much research has shown that conifers have a more conserving water use strategy compared to broad-leaved tree species (Catovsky et al., 2002; Wullschleger et al., 1998) and evergreens are more adapted to compacted soils than deciduous trees (Alameda and Villar, 2009). However, light intensity may have a significant effect on $P$. orientalis. As the canopy density of $R$. pseudoacacia decreased with an increasing degree of compaction, more light was available to $P$. orientalis, which grew underneath, improving its performance.

The leaf water content of $M$. sativa decreased while biomass increased with an increasing degree of compaction. M. sativa was well adapted to compacted plots, which was consistent with Cresswell and Kirkegaard (1995). The higher biomass may result from less intensive interspecific competition for resources such as light or because plant growth was accelerated under mild or temporary water stress (Shao et al., 2010).

\section{Conclusions}

LGM, the mixture of landfill-stabilized waste and coarse quarry waste, can be used during restoration in abandoned quarries as growing material for plants. The LSW : gravel ratio had a significant effect on physiochemical properties, such as nutrient level, water condition and physical stability, and thus the performance of plants growing in LGM. LGM with $R_{\mathrm{L}}$ ranging from $8: 1$ to $3: 7$ was suitable for plant growth, and the target species grew best when $R_{\mathrm{L}}$ was $5: 5$. When $R_{\mathrm{L}}$ was lower than $3: 7$, compaction enhanced the retention of precipitation, but the leaf water content of plants was lower or unchanged in the more compacted plots. Moderate compaction was beneficial to the survival and growth of $R$. pseudoacacia. P. orientalis and M. sativa were not significantly affected by compaction; they grew better in highly compacted area where the uppermost layer of vegetation was suppressed and thus more light was available. Compared to fast-growing broad-leaved trees, conifers and herbaceous species may be more adapted to compacted LGM, and interspecific interaction showed a significant effect on plant performance. Nutrient or pollutant leaching with the deep percolation water or surface runoff are not covered in this paper, but they are very important factors considering the longtime impacts of LGM or LSW application. Some work has been done on the chemical and hydrological properties of LSW (Zhang et al., 2017; Feng et al., 2017), but more study should be made of the environmental effects of municipal solid waste application.
Data availability. The data are provided in the Supplement.

\section{The Supplement related to this article is available online at https://doi.org/10.5194/se-8-1131-2017-supplement.}

Competing interests. The authors declare that they have no conflict of interest.

Acknowledgements. This work was supported by the R and D Special Fund for Forestry Public Welfare Industry "Key re-vegetation technology research on woodland damaged by construction" (200904030) and the Reform and Development Project of Beijing Municipal Science and Technology Commission. The publication charges were covered by the National Key R and D Program of China "Eco-security technology for coal mining bases in the Northwestern arid desert regions in China" (2017YFC0504404).

Edited by: Antonio Jordán

Reviewed by: two anonymous referees

\section{References}

Akbulut, H. and Gürer, C.: Use of aggregates produced from marble quarry waste in asphalt pavement, Build. Envirom., 42, 19211930, 2007.

Alameda, D. and Villar, R.: Moderate soil compaction: implications on growth and architecture in seedlings of 17 woody plant species, Soil Till. Res., 103, 325-331, 2009.

Amin, S. K., Youssef, N. F., El-Mahllawy, M. S., and El-Abd, H.: Utilization of Gebel Attaqa Quarry Waste in the manufacture of Single Fast Firing Ceramic Wall Tiles, Int. J. Environ. Sci., 2, 765-780, 2011.

André, A., de Brito, J., Rosa, A., and Pedro, D.: Durability performance of concrete incorporating coarse aggregates from marble industry waste, J. Clean. Prod., 65, 389-396, 2014.

Castro-Gomes, J. P., Silva, A. P., Cano, R. P., Suarez, J. D., and Albuquerque, A.: Potential for reuse of tungsten mining wasterock in technical-artistic value added products, J. Clean. Prod., 25, 34-41, 2012.

Catovsky, S., Holbrook, N. M., and Bazzaz, F. A.: Coupling wholetree transpiration and canopy photosynthesis in coniferous and broad-leaved tree species, Can. J. Forest Res., 32, 295-309, 2002.

Cerdà, A.: The influence of aspect and vegetation on seasonal changes in erosion under rainfall simulation on a clay soil in Spain, Can. J. Soil Sci., 78, 321-330, 1998.

Cohen, J., Cohen, P., and West, S. G.: Applied multiple regression/correlation analysis for the behavioral sciences, Oxon, Routledge, 2003.

Cresswell, H. P. and Kirkegaard, J. A.: Subsoil amelioration by plant roots, the process and the evidence, Soil Res., 33, 221-239, 1995.

Descroix, L., Viramontes, D., Vauclin, M., Barrios, J. L. G., and Esteves, M.: Influence of soil surface features and vegetation on 
runoff and erosion in the Western Sierra Madre (Durango, Northwest Mexico), Catena, 43, 115-135, 2001.

Duan, W. J., Ren, H., Fu, S. L., Wang, J., Yang, L., and Zhang, J. P.: Natural recovery of different areas of a deserted quarry in South China, J. Environ. Sci., 20, 476-481, 2008.

Feng, J., Zhang, C., Zhao, T., and Zhang, Q.: Rapid revegetation by sowing seed mixtures of shrub and herbaceous species, Solid Earth, 6, 573-581, https://doi.org/10.5194/se-6-573-2015, 2015.

Feng, J., Zhang, C., Zhao, T., and Zhang, Q.: Potential harmful effects of landfill stabilized waste: semi-volatile organic compounds and salinity, a case study in Beijing, China, Environ. Earth Sci., 76, 387, https://doi.org/10.1007/s12665-017-6723-5, 2017.

Forján, R., Asensio, V., Rodríguez-Vila, A., and Covelo, E. F.: Contribution of waste and biochar amendment to the sorption of metals in a copper mine tailing, Catena, 137, 120-125, 2016.

Gazi, A., Skevis, G., and Founti, M. A.: Energy efficiency and environmental assessment of a typical marble quarry and processing plant, J. Clean. Prod., 32, 10-21, 2012.

Huxman, T. E., Cable, J. M., Ignace, D. D., Eilts, J. A., English, N. B., Weltzin, J., and Williams, D. G.: Response of net ecosystem gas exchange to a simulated precipitation pulse in a semi-arid grassland: the role of native versus non-native grasses and soil texture, Oecologia, 141, 295-305, 2004.

Jeldes, I. A., Drumm, E. C., and Schwartz, J. S.: The low compaction grading technique on steep reclaimed slopes, soil characterization and static slope stability, Geotechnical and Geological Engineering, 31, 1261-1274, 2013.

Jomaa, S., Barry, D. A., Brovelli, A., Heng, B. C. P., Sander, G. C., Parlange, J.-Y., and Rose, C. W.: Rain splash soil erosion estimation in the presence of rock fragments, Catena, 92, 38-48, 2012.

Jordán, M. M., García-Sánchez, E., Almendro-Candel, M. B., Pardo, F., Vicente, A. B., Sanfeliu, T., and Bech, J.: Technosols designed for rehabilitation of mining activities using mine spoils and biosolids. Ion mobility and correlations using percolation columns, Catena, 148, 74-80, 2017.

Le Stradic, S., Buisson, E., and Fernandes, G. W.: Restoration of Neotropical grasslands degraded by quarrying using hay transfer, Appl. Veg. Sci., 17, 482-492, 2014.

Liu, Z.-D., Gao, Y., Duan, A.-W., and Gong, W. J.: Influence factors of rainfall runoff in the winter wheat field, J. Soil Water Conserv., 26, 38-44, 2012.

Luna, L., Miralles, I., Andrenelli, M. C., Gispertd, M., Pellegrinic, S., Vignozzic, N., and Solé-Benet, A.: Restoration techniques affect soil organic carbon, glomalin and aggregate stability in degraded soils of a semiarid Mediterranean region, Catena, 143, 256-264, 2016

Nadian, H., Smith, S. E., Alston, A. M., and Murray, R. S.: The effect of soil compaction on growth and $\mathrm{P}$ uptake by Trifolium subterraneum: interactions with mycorrhizal colonization, Plant Soil, 182, 39-49, 1996.
Okura, Y., Kitahara, H., Kawanami, A., and Kurokawa, U.: Topography and volume effects on travel distance of surface failure, Eng. Geol., 67, 243-254, 2003.

Rubio, M. C., Moreno, F., Belmonte, A., and Menéndez, A.: Reuse of waste material from decorative quartz solid surfacing in the manufacture of hot bituminous mixes, Constr. Build. Mater., 24, 610-618, 2010.

Safiuddin, M., Jumaat, M. Z., Salam, M. A., Islam, M. S., and Hashim, R.: Utilization of solid wastes in construction materials, Int. J. Phys. Sci., 5, 1952-1963, 2010.

Safiuddin, M., Raman, S. N., and Zain, M. F. M.: Utilization of quarry waste fine aggregate in concrete mixtures, J. Appl. Sci. Res., 3, 202-208, 2007.

Schäffer, B., Schulin, R., and Boivin, P.: Changes in shrinkage of restored soil caused by compaction beneath heavy agricultural machinery, Eur. J. Soil Sci., 59, 771-783, 2008.

Shao, G.-C., Liu, N., Zhang, Z.-Y., Yu, S.-E., and Chen, C.-R.: Growth, yield and water use efficiency response of greenhousegrown hot pepper under Time-Space deficit irrigation, Sci. Hortic.-Amsterdam, 126, 172-179, 2010.

Sharrow, S. H.: Soil compaction by grazing livestock in silvopastures as evidenced by changes in soil physical properties, Agroforest. Syst., 71, 215-223, 2007.

Tiruta-Barna, L., Benetto, E., and Perrodin, Y.: Environmental impact and risk assessment of mineral wastes reuse strategies: Review and critical analysis of approaches and applications, Resour. Conserv. Recy., 50, 351-379, 2007.

Wang, J., Zou, B., Liu, Y., Tang, Y., Zhang, X., and Yang, P.: Erosion-creep-collapse mechanism of underground soil loss for the karst rocky desertification in Chenqi village, Puding county, Guizhou, China, Environ. Earth Sci., 72, 2751-2764, 2014.

Wullschleger, S. D., Meinzer, F. C., and Vertessy, R. A.: A review of whole-plant water use studies in tree, Tree Physiol., 18, 499-512, 1998.

Xie, L.: Application of Photoshop in cartographic area calculation, Computer Knowledge and Technology, 6, 4021-4022, 2010.

Yuan, C., Lei, T., Mao, L., Liu, H., and Wu, Y.: Soil surface evaporation processes under mulches of different sized gravel, Catena, 78, 117-121, 2009

Zhang, C.-L., Feng, J.-J., Zhao, T.-N., and Rong, L.-M.: Physical, chemical and engineering properties of landfill stabilized waste, Land Degrad. Dev., 28, 1113-1121, 2017.

Zhou, C., Xu, W., Gong, Z., Fang, W., and Cao, A.: Characteristics and fertilizer effects of soil-like materials from landfill mining, CLEAN - Soil Air Water, 43, p. 940, 2015. 